TI 2014-063/I

Tinbergen Institute Discussion Paper

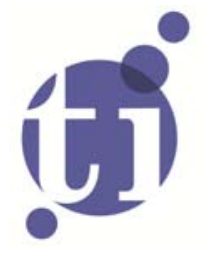

\title{
Bidding for Nothing? The Pitfalls of overly Neutral Framing
}

Peter Dürsch ${ }^{1}$

Julia Muller²

1 University of Heidelberg, Germany;

2 Erasmus School of Economics, Erasmus University Rotterdam, and Tinbergen Institute, the Netherlands. 
Tinbergen Institute is the graduate school and research institute in economics of Erasmus University Rotterdam, the University of Amsterdam and VU University Amsterdam.

More TI discussion papers can be downloaded at http://www.tinbergen.nl

Tinbergen Institute has two locations:

Tinbergen Institute Amsterdam

Gustav Mahlerplein 117

1082 MS Amsterdam

The Netherlands

Tel.: +31(0)205251600

Tinbergen Institute Rotterdam

Burg. Oudlaan 50

3062 PA Rotterdam

The Netherlands

Tel.: +31(0)10 4088900

Fax: $+31(0) 104089031$

Duisenberg school of finance is a collaboration of the Dutch financial sector and universities, with the ambition to support innovative research and offer top quality academic education in core areas of finance.

DSF research papers can be downloaded at: http://www.dsf.nl/

Duisenberg school of finance

Gustav Mahlerplein 117

1082 MS Amsterdam

The Netherlands

Tel.: +31(0)20 5258579 


\title{
BIDDING FOR NOTHING? THE PITFALLS OF OVERLY NEUTRAL FRAMING
}

\author{
PETER DUERSCH \\ University of Heidelberg
}

\begin{abstract}
JULIA MÜLLER
Erasmus University Rotterdam $\mathcal{E}$ Tinbergen Institute
\end{abstract}

\begin{abstract}
Neutral framing is a standard tool of experimental economics. However, overly neutral instructions, which lack any contextual clues, can lead to strange behavior. In a contextless second price auction for a meaningless good, a majority of subjects enter positive bids - a case of cognitive experimenter demand effect. Subjects bid positive amounts because this is what they think they are tasked with in the experiment. Adding a second auction that has a context drastically reduces the positive bids in the meaningless first auction by reducing the cognitive experimenter demand effect.
\end{abstract}

Keywords: context, neutral framing, experimenter demand effect; experiment; second-price auction.

JEL Classification Code: C90, D44.

E-mail addresses: peter.duersch@awi.uni-heidelberg.de, jmuller@ese.eur.nl.

Date: May 26, 2014.

We thank Christoph Vanberg and Israel Waichmann for valuable comments. Financial support by the DFG through SFB 504 is gratefully acknowledged. 


\section{INTRODUCTION}

Experiments in economics typically present their instructions in a neutral frame, without context. More complicated experiments may use a small amount of framing to further the understanding of the mechanisms used in the experiment, but even these experiments avoid the inclusion of any contextual clues that could suggest 'correct' behavior. ${ }^{1}$ However, there is a drawback to overly neutral framing.

We report an experiment which shows that context helps subjects to find the meaning of the task described in the instructions. Specifically, in the absense of any context, a majority of subjects in our experiment enter positive bids in an auction for a meaningless activity, despite having been checked on their understanding of the mechanism of the auction. If the experiment is conducted with more context, connected to a new, second, auction where a potentially reasonable activity is sold, the bids in the meaningless auction drastically decline. A possible explanation is that context helps to reduce an experimenter demand effect (EDE) which is present in the auction without context. Once subjects can identify some sensible task in the experiment (e.g. figuring out the value of the good in the second auction and bidding accordingly), they are less likely to take an action in a non-sensible task simply because that action is available.

Experimental economists use the term "experimenter demand effect" to describe the fact that the experimenter might influence the subjects' decision in the experiment. ${ }^{2}$ This can lead to the experimenter's concluding that the tested hypothesis is true, even though the effect is solely due to the experimenter's demand. Zizzo (2010) distinguishes the EDE into social EDE and cognitive EDE. In social EDE, the subjects act as the experimenters (explicitly) ask them to. A famous example is the experiment by Milgram (1963), where subjects were asked to administer electrical shocks. In contrast, in cognitive EDE, subjects do not react to a direct demand. Instead, they react to a perceived implicit demand. As participants in an experiment, the subjects "try to make sense of the unfamiliar and incompletely defined experimental environment" (Zizzo, 2010). That is, the subjects try to figure out

\footnotetext{
${ }^{1}$ See Davis and Holt (1993); Friedman and Sunder (1994). A discussion of neutral framing is given in Abbink and Hennig-Schmidt (2006).

${ }^{2}$ Experimental psychologists have long studied the same topic under the name of the "Hawthorne effect" (Adair, 1984).
} 
what they are supposed to do. Our finding is an example of cognitive EDE, since the subjects are not explicitly asked to bid, but from the lack of context, construe that they are being asked to bid.

\section{The Experiment}

The experiment consists of two treatments: one auction $(1 A)$ and two auctions $(2 A)$. At the heart of each treatment is a second price auction. In this second price auction, we auction off the right to "destroy" a paper envelope. ${ }^{3}$ The subjects were anonymously matched into bidding groups of three. The highest bidder won the right to destroy the envelope and had to pay the second highest bid. In the case of tied highest bids, one bidder was randomly selected as the winner. The allowed range of bids was $0 \ldots 10$ euro, with a stepsize of 0.01 . Payment for the bid was not out of pocket, but implemented via previous earnings in the experiment. ${ }^{4}$

Before the auction took place, the subjects had to answer some test questions that checked whether they understood that the winner would only have to pay the second highest bid, that there would always be a winner of the auction, and that it was possible to ensure a cost of zero by bidding zero. ${ }^{5}$

In treatment $1 A$, the subjects bid in one auction, auction $N C$. The auctioned good is the right to destroy one envelope. The subjects received no background information about the envelope, nor were they given any reason why the envelope should or should not be destroyed. In treatment $2 A$, the subjects bid in two auctions: auction $N C$ and auction $C$. Auction $N C$ was identical to the auction in treatment $1 A$ described above. In contrast to the context-free auction $N C$, auction $C$ was embedded in a larger context within treatment $2 A$. In $2 A$, all subjects were matched with an additional non-bidding subject. At the start of $2 A$, all bidding subjects had to perform a tedious real effort

\footnotetext{
${ }^{3}$ The act of destroying was not further specified. Most subjects opted for either crossing out the envelope with pens, or ripping the envelope into pieces.

${ }^{4}$ In the case of $2 A$, the previous earnings consisted of a show-up fee and the money gained in a real effort task. In the case of $1 A$, a separate, unconnected experiment was run beforehand and the subjects could use their earnings from this experiment to bid. In both cases, the average earnings were similar.

${ }^{5} \mathrm{~A}$ full description of the instructions and test questions can be found in the online appendix: http://www.uni-heidelberg.de/md/awi/professuren/with2/Duersch -Mueller-BfN-appendix.zip and in Duersch and Müller (2013).
} 
task. Afterwards, the non-bidding subjects had the choice to allocate the earnings from that task either fully to the bidding subjects, who worked, or to take $80 \%$ of the earnings for themselves and leave the bidding subjects with just $20 \%$.

The envelope, which could be destroyed when winning auction $C$, is no longer without context, but connected to this allocation decision. To be precise, it contained the $80 \%$ of earnings which the non-bidding subject allocated to themself. Thus, the real effort task and allocation decision form a strong context for the bidding. ${ }^{6,7}$

The bids in treatment $2 A$ were elicited via the strategy method. The subjects gave bids for both auctions. Afterwards, one auction was randomly selected to come into effect. Only the winner of the selected auction got to destroy an envelope and had to pay the second highest bid of that auction.

The experiment was conducted in the laboratory of the University of Heidelberg and the laboratory of SFB 504 in Mannheim. In all, 33 subjects participated in treatment $1 A$ (in three sessions); 40 subjects participated in treatment $2 A$ (in two sessions). Out of these, 30

\footnotetext{
${ }^{6}$ Destroying the envelope was not equivalent to reducing the allocator's payoff. Instead, in a separate stage before the auction, the bidding subjects decided whether or not to reduce the allocator's payoff by exactly the amount present in one envelope (a few allocators decided to leave all earnings with the working subjects, we drop those observations from the analysis). This reduction happened regardless of the outcome of the auction. Thus, while the real effort task and the allocation decision form a strong context of bidding, the bidding was not equivalent to punishing. There was no payoff change for any other person when winning the auctions. Of course the winner would still pay the second highest bid. To test whether filling the envelope with paper money instead of leaving it empty changed the bids, we ran one-half of $N C$ with empty envelopes (as in $N C$ in treatment $2 A$ ) and the other half with envelopes filled with paper money (as in $C$ in treatment $2 A$ ). There was no significant difference in bids (two-sided MWU test, $p=0.428$, obs. $=33$ ), therefore we pool the data.

${ }^{7}$ Using a real effort task and an allocation decision to provide a context for the bidding in auction $C$ of treatment $2 A$ might not seem very intuitive. In fact, this is due to our reusing the data from an experiment with a very different research question: whether subjects are willing to bid to personally punish (Duersch and Müller, 2013). However, auction $C$ is not the main interest here. We want to compare the auction without context, $N C$, in two situations: one standing alone, and one while being contrasted with an auction with some form of strong context. The exact nature of that context is not important.
} 
subjects were bidders in the auctions and 10 subjects allocators. All recruitment used ORSEE (Greiner, 2004).

\section{Results}

Table 1 shows the average bids in the auctions. When the auction without context, $N C$, was conducted on its own in treatment one auction, $1 A$, a majority of subjects (52\%) made positive bids. However, when auction $N C$ was set in contrast with an auction with context (auction $C$ ) in treatment two auctions, $2 A$, far fewer subjects bid $(17 \%)$.

\begin{tabular}{|c|c|c|c|c|c|c|}
\hline treat. & auction & obs. & avg.(SD) & max & bid $>\mathbf{0}$ & bid=0 \\
\hline $2 \mathrm{~A}$ & $\mathrm{C}$ & 30 & $0.335(0.98)$ & 4.00 & $63 \%$ & $37 \%$ \\
$-\overline{\mathrm{NC}}$ & 30 & $0.03(0.10)$ & 0.50 & $17 \%$ & $83 \%$ \\
\hline 1A & $\overline{\mathrm{NC}}$ & $-\overline{33}$ & $0.67(1.78)$ & 6.50 & $-\overline{52 \%}$ & $4 \overline{8} \%$ \\
\hline
\end{tabular}

TABLE 1. Bids (in Euro)

The bids in auction $N C$ were significantly different across treatments (two-sided MWU, $p=0.007$, obs.=63). Even more, the bids in auction $N C$ in treatment $1 A$ were so high that they were not significantly different from the bids in auction $C$ in treatment $2 A$ (two-sided MWU, $p=0.431$, obs. $=63)$. This is despite the fact that the bids within the two auctions of treatment $2 A$ (auction $N C$ and $C$ ) were significantly different (Wilcoxon signed rank test, two-sided, $p=0.015$, obs. $=30$ ).

\section{Discussion}

Does our treatment $1 A$ imply that people have a willingness to pay up to $€ 6.50$ for the right to destroy an envelope? We think not. ${ }^{8}$ It is much more likely that the overly neutral framing in $1 A$ leads, via a complete lack of context that could rationalize not bidding, to a cognitive experimenter demand effect of being implicitly asked to bid. As evidence of this, bidding in the contextless auction is much lower when a different auction with some context is present, so that subjects

\footnotetext{
${ }^{8}$ The average bid of $€ 0.03$ in auction $N C$ of treatment $2 A$ might be an indication of the real value subjects place on destroying an envelope.
} 
can rationalize the aim of the experiment as being about that other context instead of the contextless destruction of an envelope. ${ }^{9}$

There is some anecdotal evidence for the cognitive experimenter demand effect as well. While being handed her payment in treatment $1 A$, one subject mentioned that she "wanted to help" the nice experimenters (she entered one of the highest bids in the treatment). Apparently, she must have felt that in a task where only bidding is possible, and no context provides a hint whether bidding is "good" or "bad," high bids must be what the experimenters are looking for. No subject in treatment $2 A$ ever made an analogous statement.

Lei, Noussair, and Plott (2001) use a similar design, where the results of a task are evaluated before and after adding a second task. However, while they find some differences after adding the second task, their main variable of interest (average price in an asset market) remains unchanged. One important difference between their design and ours is the amount of context of the second, added, task. In our case, the second task provides more context, and the bids in the first task decline. In their design, the context of both tasks is similar, suggesting that adding tasks only reduces cognitive EDE if the added tasks allow an easier construal of the task because of the presence of more of a context.

\section{REFERENCES}

Abbink, K., And H. Hennig-Schmidt (2006): "Neutral versus loaded instructions in a bribery experiment," Experimental Economics, 9(2), 103-121.

AdAIR, J. G. (1984): "The Hawthorne Effect: A Reconsideration of the Methodological Artifact," Journal of Applied Psychology, 69(2), 334-345.

Davis, D. D., And C. A. Holt (1993): Experimental Economics. Princeton University Press, Princeton, New Jersey.

Duersch, P., And J. Müller (2013): "Taking Punishment into Your Own Hands: An Experiment," mimeo.

\footnotetext{
${ }^{9}$ Note that the low average bid in auction $N C$ of treatment $2 A$ also makes competing explanations for bids in treatment $1 A$, such as "desire to win" (van den Bos, Li, Lau, Maskin, Cohen, Montague, and McClure, 2008) or misunderstanding the second price auction, less likely.
} 
Friedman, D., And S. Sunder (1994): Experimental Methods. A Primer for Economists. Cambridge University Press, Cambridge.

Greiner, B. (2004): "An online recruitment system for economic experiments," in Forschung und wissenschaftliches Rechnen 2003, ed. by K. Kremer, and V. Macho, chap. GWD Berich, pp. 79-93. Gesellschaft für Wissenschaftliche Datenverarbeitung, Göttingen.

Lei, V., C. N. Noussair, and C. R. Plott (2001): "Nonspeculative Bubbles in Experimental Asset Markets: Lack of Common Knowledge of Rationality vs. Actual Irrationality," Econometrica, 69(4), 831-859.

Milgram, S. (1963): "Behavioral Study of Obedience.," Journal of Abnormal and Social Psychology, 67(4), 371-8.

van den Bos, W., J. Li, T. Lau, E. Maskin, J. D. Cohen, P. R. Montague, and S. M. MCClure (2008): "The value of victory: social origins of the winner's curse in common value auctions.," Judgment and decision making, 3(7), 483-492.

Zızzo, D. J. (2010): "Experimenter demand effects in economic experiments," Experimental Economics, 13(1), 75-98. 